\title{
Innovating Relations - or Why Smart Grid is not too Complex for the Public
}

\author{
Lea Schick and Brit Ross Winthereik
}

\begin{abstract}
Revamping the electricity infrastructure to allow for an increased usage of renewable energy sources is a matter of concern in many parts of the world. In Europe, a major policy question is how to move energy demand to periods with surplus of renewable energy in the grid. In this paper we follow prominent Danish and German delegates working towards realizing the intelligent electricity infrastructure commonly known as 'smart grid' envisioned to be a significant actor in the management of renewable energy. Starting out with a view on smart grid that recognizes it as a partially existing object, we attend to its gradual emergence by focusing on two models and a metaphor evoked to represent smart grid development. As we contrast and compare these representational objects, smart grid emerges as a potential 'thing'. Following Latour a 'thing' is a gathering of many actors agreeing and disagreeing about what the thing 'is' (its ontological status). In the paper we show how smart grid innovation both emerges - and fails to emerge - as an object of relevance to a broader public. Even though users play an important role in the imagination of experts, a gap remains between the experts and those who smart electricity infrastructures will come to affect. Concerned with this gap we argue that Science and Technology Studies must pay attention to how smart grid development gets constructed as a public problem in specific imaginative spaces of opportunity and closure.
\end{abstract}

Keywords: Smart grid, innovation, public problems

\section{Introduction}

Above the door to the long and narrow conference room at the Siemens headquarters in Munich the Danish flag is welcoming Her Royal Highness Princess Benedikte and the participants in this afternoon's innovation delegation meeting. The delegates are lined up behind their chairs: ten Danes working on smart grid research and devel- opment, all of us participants in this Innovation Delegation Trip to Germany. On the other side of the table are the Germans, all of them prominent actors within smart grid development. We are standing there; lined up facing one another as two armies of experts, ready to innovate a new energy system with 'smart green homes' for future energy users to inhabit. As the Princess enters the room, it becomes deadly quiet and 
all one can hear is the absence of the royal trumpets. At the very end of the narrow room, behind a large decoration of flowers, the Princess reads aloud her short speech in which she explains how immensely important it is for Denmark to take on a leading role in smart grid development. It is "one of our time's utmost crucial challenges for scientists and engineers to turn around our energy system, make it more green, and create a better future for everybody".

(field notes, June 2012)

In this paper we analyse European smart grid development by attending a delegation trip to Germany organised by the Innovation Center Denmark, which is an initiative by the Danish Ministry of Foreign Affairs ${ }^{1}$. The theme of this particular trip is the Smart Green Home and the aim is to "to initiate a dialogue between Danish researchers and Danish SMEs [small and mediumsized enterprises] with German knowledge institutions as well as key industrial players" in order to "realise the potential of an energy saving grid and to reduce the overall energy consumption in the home" ${ }^{2}$.

The smart green home is a central element in the intelligent energy infrastructure called the smart grid. The smart grid is envisioned to become intelligent by attaching information and communication technology (ICT) to the existing power grid. ICT shall measure and regulate energy production and energy consumption in a future with renewable energy generation. The promise of the smart grid is that it will make energy consumption flexible and manageable so that it can be controlled to follow fluctuating energy production from renewable energy sources such as wind and sun. "We need to do laundry when the wind blows", is a popular way of explaining how energy flexibility will affect ordinary citizens. Private households and consumers are thus imagined to play a different, and perhaps more active, role in the energy system.

Despite an enthusiastic belief in the doability of the project - generally in the field, and in particular on the delegation trip from which we report - there are among smart grid developers a consensus about innovation of smart grid as being a very complex and difficult task. In a Danish context the innovation of smart grid is often described as a complicated jigsaw puzzle ${ }^{3}$ : “To develop an 'intelligent' power system - a Smart Grid - is like putting together a jigsaw puzzle with some of the pieces either missing or not quite fitting." (Energinet. $\mathrm{dk}, 2011: 5)$. One of the 'pieces' that smart grid developers have a hard time getting 'in place' is the energy consumer ${ }^{4}$. This figure is sometimes being referred to as the user, other times as a consumer being reconfigured into a prosumer ${ }^{5}$, and yet other times as humans or people ${ }^{6}$.

In this article we attend to an innovation space, in which imagined users, technological experts, energy and ICT infrastructures, visualizations and scientists come together. To account for the negotiations in this space of what smart grid 'is', we ground our thinking in the second wave of actor-network-theory inspired Science and Technology Studies (STS). Following Jensen (2010: 19-29), whose work builds on Bruno Latour's (following Michel Serres') notion of the quasi-object (Latour, 1976, 1999), we approach smart grid as a partially existing object. Conceptualising smart grid as 'partially existing' indicates that its ontological status is uncertain in the sense that there are fundamental differences in how actors in the described innovation space see smart grid. Focusing on smart grid as partially existing is not done to 'mock' anyone participating in smart grid development or to indicate that it does not exist. In fact, a number of technologies imagined to be part of a smart 
energy infrastructure, including smart meters, electrical vehicles, wind turbines, and energy management systems, are on the market and have been for some time. While these technologies exist smart grid as such is under development - and as we show - is imagined to be working in different ways.

Thus, describing smart grid as 'partially existing' is done to highlight the question of how this infrastructure gets stabilized and by what means. Drawing on Latour's notion of 'things' (Latour \& Weibel, 2005) as entities that - opposite objects - should never be considered self-contained, coherent, or stable (see also Mol, 2002). Analysing an emerging energy infrastructure as a 'thing' thus accounts for the complex character of such infrastructure as being always rich and complicated entanglements of humans and technologies, discourse and materiality, nature and politics. Latourian 'things' are always gatherings of many participants agreeing or disagreeing on the nature of 'it'. When a thing becomes black boxed, that is when enough actors agree on the character of its existence, it can appear as a steady and self-contained object, as a 'matter of fact' (Latour, 2004). When, in contrast, an infrastructure, is about to 'be born' it provides a great window for studying its 'thinginess' 7 (Jensen, 2010). It is this thinginess, the many participating concerns and the gathering of actors around smart grid, which is the main concern of our study.

In order to demonstrate the partial existence of smart grid we analyse two visual representations; that is, two technical illustrations of how future smart grids might be designed. We refer to these representations, which allow us to see the smart grid as a contested and emerging entity, as 'smart grid objects'. Opting for this approach, we argue, has ontological implications in the sense that it brings into view a smart grid that is not simply gaining in technological maturity and stability.
Instead, its very existence is coming into being and changing through interacting concerns of the heterogeneous network of actors partaking in its development. Thus, the smart grid objects that we describe below - two diagrams of smart grid presented on power point slides - are not downscaled versions of one, singular and 'real' smart grid. Rather, we see them as performing smart grid partiality and complexity without ever adding up to a 'whole' (Mol \& Law, 2002). We add to our description of the smart grid models a metaphor for collaboration - the smart grid family. This metaphor, borrowed from our informants, creates a bridge to our discussion of smart grid innovation as being among others a matter of a group of actors formulating a public problem.

Attending to smart grid representations allows us to present smart grid as an entity emerging in a space, in which imagined energy users, technological experts, specialists on 'humans', the STS researcher, the royal family, and visual representations all participate. By studying smart grid as a partially existing object gradually emerging in a space of social and technological actors, we are also enabled to see how particular relations between experts and non-experts emerge.

We suggest that smart grid innovation is happening in an imaginative space of relations and non-relations, of opportunity and of closure. By attending to alignments and disconcertments (exemplified with respect to the developers' concern with the role of the energy user) both the sturdiness and the fragility of smart grid it's 'thingness' (Latour, 2004: 237, 245) are brought into view.

\section{Studying Smart Energy in the Making}

Though the following analysis focuses mainly on the three days of the delegation trip, the analysis is empirically grounded in two years of fieldwork primarily among 
Danish smart grid developers ${ }^{8}$. Our choice of focusing on a particular event highlights our approach to ethnographic stories as complex entities enacting wholes and parts in continuous variation (Jensen, 2013 online first; Winthereik \& Verran, 2012). Lasting three very intense days, the delegation trip turned out to be a rich resource for teasing out smart grid innovation as an issue of 'public' as well as 'theoretical' importance. The participants taking part in this trip were mostly prominent players in the development of smart grid. Participation required all delegates, including the first author, to present their work on smart grid for the various companies and institutions visited ${ }^{9}$. The format of the trip - presentations and discussions comparing smart grid development in the two respective countries - meant that essential characteristics, challenges, and divergences were articulated. This allowed for observation of and participation in discussions of the interests and concerns of Danish as well as German delegates. As the delegation trip formed a 'learning environment' it was unproblematic to take ethnographic notes during the formal program. The observations made during the informal activities were written up whenever this was possible after the event. In the following, we have kept the names of the companies behind the models, but have anonymised the presenters by giving them pseudonyms.

In our analysis of the Power Point slides we are inspired by Latour's text Visualisation and Cognition: Drawing Things Together (1986). Here he argues that when studying how new things come into being - be it knowledge or material things - there has been a tendency to pay too much attention to discourses, language, and to the protagonists. However, it is just as important, he says, to attend to nondiscursive, material elements i.e. diagrams, signs, visualizations and models partaking in the construction work. Latour, and others with him, study these objects by attending to their 'inscriptions' (see also: Akrich, 1992; Latour, 1992; Suchman, 2007; Winthereik, Johannsen, \& Strand, 2008).

What is so important in the images and in the inscriptions scientists and engineers are busy obtaining, drawing, inspecting, calculating and discussing? It is, first of all, the unique advantage they give in the rhetorical or polemical situation. "You doubt of what I say? I'll show you." And, without moving more than a few inches, I unfold in front of your eyes figures, diagrams, plates, texts, silhouettes, and then and there present things that are far away and with which some sort of two-way connection has now been established. (Latour, 1986: 13).

Latour argues that technical drawings make it possible for their protagonists to control and manage large, not-yet-quite-existing machines. In our case of infrastructure development, the models create what Latour describes as a two-way connection to the future and back again (Latour, 1986: 10). By visualizing 'the future', power and potentiality is allocated to the presenter of the model, who can hopefully convince the audience that his proposal for smart grid should function as the roadmap to the future. Latour argues that the power of visual models lies in their quality as 'immutable mobiles'; that is they can be moved around. For example, they can be flown to Munich and showed in several institutions and companies without being significantly distorted (Latour, 1986: 7).

As visualizations align and mobilize actors, they create new 'gatherings'; that is spaces for discussion and generative imagination. Such spaces emerge between 
discourse and physical representation between the presenter, his/her model, and the audience. This opens up "a space of imagination and opportunity - a space where subjectivity is constituted and acted out." (Hetherington, 2011: 459). Thus, when we analyse and discuss the smart grid models we do not see them as more or less accurate, individual roadmaps to 'the future', but as working objects embedding particular subject-positions and performing futures. We thus explore how the inscriptions enact particular futures for humans to inhabit, and we analyse how the relations between smart grid objects and the delegates make innovation happen.

\section{Smart Grid Objects: Two Power Points and a Metaphor}

Now, let us return again to Bavaria, where the old medieval town of Munich hosts the smart green homes delegation trip. Here we encounter the Danish-German delegation, puzzling about how to transform contemporary energy infrastructures based on copper cables and centralized production into intelligent and decentralized power generation based on renewable energy sources and ICT.

The first presenter is Helmut Smith (pseudonym) from a consultancy managing the federal German network for smart grid research and implementation, 'EEnergy, Smart Grid made in Germany' ${ }^{10}$ One of his 60 slides maps EEnergy's vision for the future German smart grid (figure 1). "This model", Smith emphasizes, "is the core model for the smart grid, according to which all EEnergy projects work. This is common knowledge for smart energy made in Germany" (Field notes, June 2012). In this model the smart grid is made up by layers, which Smith refers to as 'worlds'. The big challenge, he says, is: How to connect these worlds?

Let us take a closer look at the model. It presents a series of circles around a core. Arrows indicate movements between the circles. The inner circle is labelled the 'Closed System Level'. This 'world' is made up by

\section{ICT links the energy system's worlds}

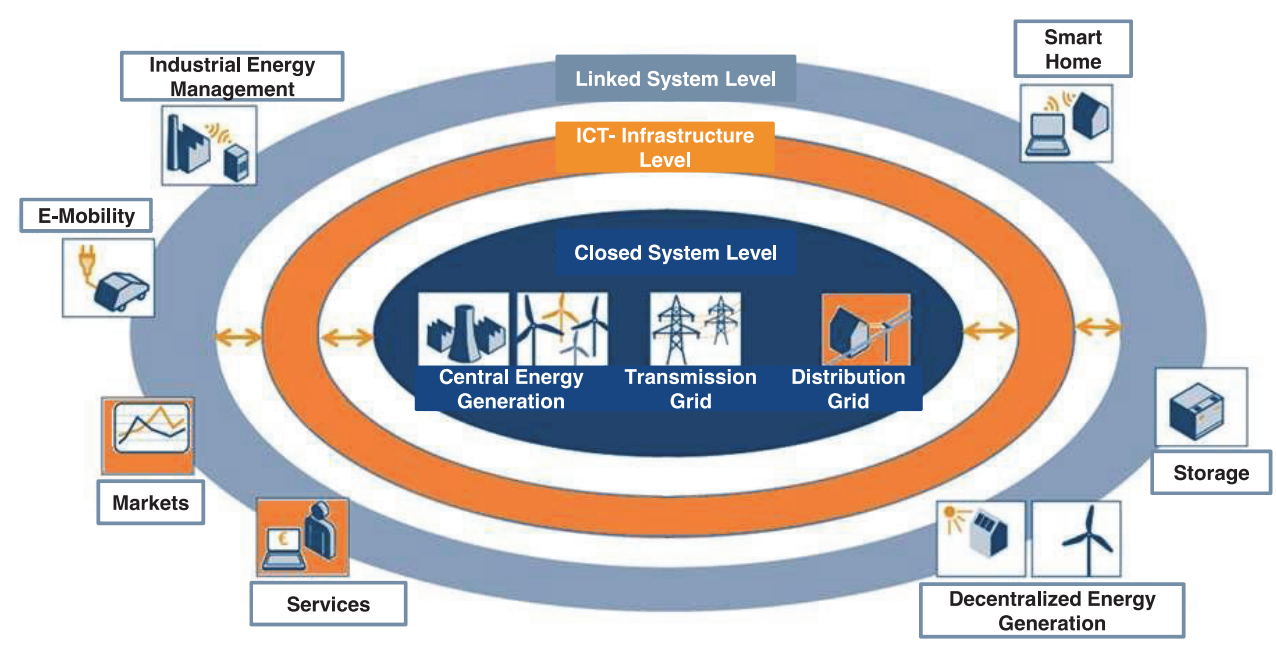

Figure 1. EEnergy's smart grid model. 
centralised, large-scale energy generation sites (coal, nuclear, ${ }^{11}$ and big wind and solar farms). It is thus the part responsible for the physical production, transmission and distribution to the grid. This is similar to the existing energy infrastructure, only with more renewable energy, and this is where the challenge emerges.

As fossil energy sources are replaced by decentralized renewable source from private photo-voltaic units, distributed wind turbines and solar panels, also gathered under the umbrella-term Distributed Energy Resources (DER), energy production is no longer under the control of big companies and the stability of the 'Closed System Level' can, according to Smith, no longer be taken for granted. The reason is that, while in today's centralized energy regime it is fairly easy to balance energy production to fit to energy consumption, this is not the case for a distributed system with fluctuation energy generation varying with sun and wind. In order to balance the system and avoid frequent blackouts, the many distributed production sites will have to be constantly measured and information sent to a centralized management unit. Smith explains that this part of the energy system, should remain a closed, stable, centralized, and secure system.

Surrounding the inner circle is the 'Linked System Level'. This 'world' is made up of DER and of so-called smart energy devices. This circle represents a large number of newcomers to the energy system; newcomers who are unstable, fluctuating and difficult to manage. ICT is thus envisioned as the mediator and manager between the new 'world' of smart energy and the more stable inner core of the system. According to Smith, the presence of fluctuating actors of the linked system level makes the energy system flexible, which is why this layer is also described as 'smart energy'12. The smartness in smart grid equals energy consumption being made flexible and controllable so that it can constantly be fitted to the fluctuating and uncontrollable energy production from renewable energy sources. According to EEnergy the secret behind the smart energy world and the management of energy consumption is an intelligent market platform: an 'energy stock exchange'13 - referred to as 'markets' in the model. By constantly measuring and communicating both energy generation and consumption, the prices of electricity will vary and reflect demand and response. Thus, electricity will be more expensive when generation is low and cheap when the wind is blowing or when the demand on electricity is low. 'Smart green homes', industries, and electrical vehicles (EVs) are made 'smart grid ready' by being all connected to the energy management systems, which EEnergy has anthropomorphized and named the 'Energy Butler': "you train the butler, tell him to have the car charged before 8 am and have the dish washer finish before $8 \mathrm{pm}$ and then he listens to the energy price signals [energy-market] and makes the decisions on when to start the devices in order to get a good price", Smith explains (field notes June 2012). As researchers being interested in delegation of agency and responsibility to non-human agents, we might take this personification of technological devices even further and conceptualize cars and smart houses as 'energy-brokers' constantly dealing energy between the consumers and the grid. 'Energy brokers' buy energy when the price is low, and sell it back when the return-rate is good. A crucial connection point between smart grid and smart house is the 'smart meter'; an enhanced electricity meter, which can make real-time readings. The smartness resides in the fact that the meter constantly communicates with the grid in order to get information on the load in the grid and real-time prices. And the meter can report the house's energy consumption 
to the grid, which is constantly up-to-date with how much electricity each house is using.

In the model we see how smart grid consist of a growing number of objects being put into relations with one-another. As this happens, they come to form a 'whole, which outlines a space for future users of the grid. In this EEnergy model the users are imagined to live on the outside of the smart energy layer and only interact with the system through their smart energy devices. In the following section we show how Smith's smart grid model is both strengthened and challenged by presentations by the Danish delegates.

During his lengthy presentation, Smith is frequently 'interrupted' by Danish delegates who are clearly very engaged and eager to discuss various issues including technological platforms, German versus Danish policies, and conceptions of the different actors' roles in the future grid. The atmosphere in the room is relaxed and friendly and seems to invite the participants in the room to think with Smith and with one-another. Smith ends by saying that now that he has talked for a full five minutes without being interrupted: it must be time to stop.

After the break the ten Danish delegates each have 10 minutes to give a pitch on their respective work and various different versions of smart grids are introduced. This model is presented by Jakob Møller-Jensen (pseudonym) from the company Spirae.dk.

Møller-Jensen talks about the different elements of smart grid - both centralised and decentralised energy production, prosumers, and smart energy devices - as being connected as 'nodes in a network' rather than worlds centred around largescale energy generation, as in EEnergy's model. The nodes are connected by a double-track infrastructure where both electricity and digital communication about energy consumption and production are bidirectional. Both power and data are

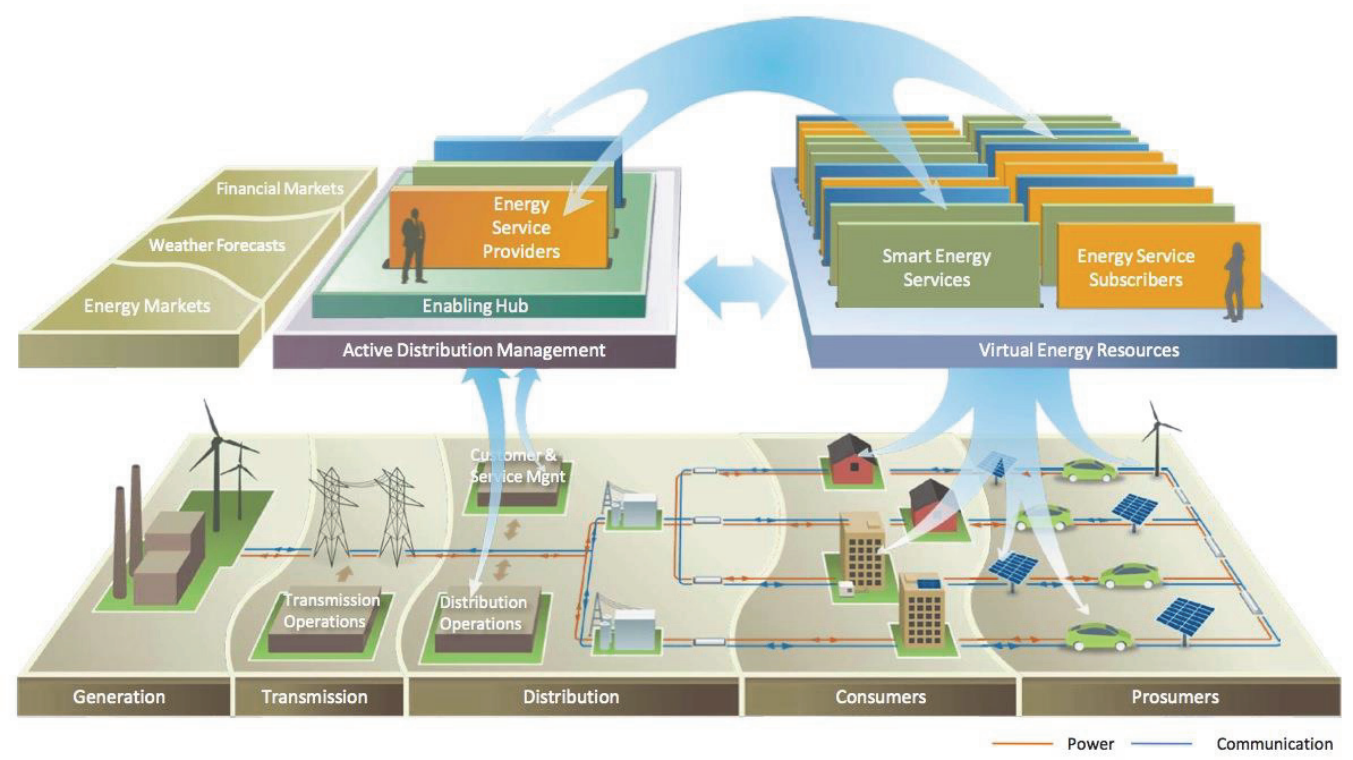

Figure 2. Spirae.dk's smart grid model. 
flowing from distributor to consumer and from consumer to distributor.

On top of the ground-layer, hovers a virtual layer consisting of non-physical components with inputs from 'abstract' elements such as the 'financial markets', 'energy markets', and 'weather forecasts', which are all part of determining the prices of electricity. The big square 'ceilings', that is the 'Active Distribution Management' (the system that balances production a and demand) and the 'Virtual Energy Recourses' (energy services) magically float over the transmission/distribution grid and the consumer/assets grid. These 'ceilings', representing the ICT-layer, creates the spine onto which the 'smart energy' devices and applications can be connected.

Both companies imagine a future where ICT is absolutely crucial for making the existing electrical grid 'smart' and for making 'smart energy' be the result of its workings. With ICT it should be made possible to constantly measure and manage energy generation and consumption and balance those to fit one another. Møller-Jensen, Smith, and all of the other participating delegates seem to agree that the smart grid is made up of the traditional electricity infrastructure plus the 'new' ICT infrastructure. Both presentations describe ICT as 'glue' binding together the many elements of the future grid. And, in both cases, ICT is ascribed the role to enable the smart grid, by facilitating the inclusion and success of the smart energy actors, making the grid flexible and adaptable. However, the interesting differences between the two models become visible when comparing how they inscribe (partly similar and partly different) relations between the infrastructure and its users.

As both models visualize, 'smart energy' is about rethinking what energy consumption is - in business as well as in private homes. Electricity consumption, and therefore electricity consumers, it is envisioned by the presenters, will have to change by becoming flexible and adaptable to fit to energy production at any time. The prosumer seemed to be a popular figure as it was mentioned in several presentations during the trip.

While the EEnergy model depicts the smart energy components as part of 'the outer world', Spirae.dk's model depicts such entities in a less structural manner. Smith emphasizes again and again that the user should not experience the complexity of the system, but rather live on the outside of the system. In Spirae.dk's model the smart consumer figures as a node in the network on the same level as any technological object; various energy components are thus imagined inhabiting the same world. In this vision, ICT and people develop the system and provide its smartness together. They do so by 1) creating services on top of the ICT platform, and 2) by feeding data about their consumption habits back into the system. Spirae.dk distinguishes between 'energy service providers' (represented by a man) and 'energy service subscribers' (represented by a woman), and introduces the idea that this gendered consumer subscribes to different services, which in turn enables the distribution companies (or new third party businesses) to control smart grid ready home appliances from a distance.

Whereas EEnergy's vision integrates these services together with the physical smart energy appliances in their smart energy layer, Spirae.dk's 'smart energy' container includes only virtual applications and services. Møller-Jensen makes an analogy to Apple's business model notably the innovation of the APP-platform. This platform is robust enough to build many reliable apps on, but at the same time easy to use and flexible enough to allow for all sorts of imaginable and not-yet-imaginable content/apps. Likewise, for Spirae.dk, 
ICT should create a solid and stable foundation, on which users and developers can build new and yet partially unknown and unforeseeable energy services (apps) and where assets can grow. Møller-Jensen argues that the engineers' innovation task is not to come up with fixed solutions, but rather to build the perfect platform on which other actors can construe content. They should "transform the electric grid into a platform for creating and delivering innovative energy applications", which must "support multiple business models" (field notes June 2012).

To sum up, both models inscribe particular subject-positions to future electricity consumers. However, in Spirae. dk's model the electricity consumer figure centrally as a participating prosumer and is thus assigned an altogether different role and a greater agency and responsibility for making the smart grid a success than is the case in EEnergy's model. Here the implementation of a perfect technological system is what makes the consumer 'smart'.

\section{Problematic prosumers and a call for expertise on human beings}

In a recent paper Cotton and Devine-Wright (2010) point out that the experts, who are responsible for developing electricity networks often refer to the affected publics as users and consumers. The problem with categorizing publics as consumers, Cotton and Devine-Wright argue, is that consumers are kept passive and not engaged in infrastructure planning (Cotton \& DevineWright, 2010: 29). We agree with the position that top-down design and planning is problematic if it does not take into account the affected social groups. However, in the case of smart grid it is crucial to be attentive to the kinds of subject-positions that an emergent smart grid produces. Put differently, we simply cannot assume that the categories of 'consumer', 'prosumer' or 'user' come to make sense in the everyday practices of the people these labels are developed to be describing (see also Sofoulis, 2011). In pointing to the smart grid as an emergent infrastructure, whose effects are as yet uncertain, we analyse incongruent actors such as Power Point slides, a princess, and a metaphor for collaboration - the smart grid family.

Both Smith and Møller-Jensen emphasized that smart grids are extremely complex systems consisting of both humans and technology. Humans were the ever-present challenge to the delegates throughout the trip. Most of the delegates (most of whom were trained as engineers) regarded it as much easier to design ICT, which can act for the consumer and thus implement flexible energy consumption, than it is to make the consumers change their behaviour actively. Despite this there was a general consensus that, ultimately, successful implementation of smart grid depends on getting people on board and involved. But dealing with humans seemed to be a very difficult and un-familiar task, and the smart grid developers felt certain that they did not have the necessary expertise. The smart grid developers seemed quite happy to deal with technologies and material challenges, but as soon as humans were 'added' and activated, it became too complicated and they saw a need for new experts with 'know-how' on humans to become involved.

For example, in his presentation Smith specified that "there is a big gap between engineers and users when designing smart meter interfaces because engineers don't really understand that ordinary people do not find numbers and graphs sexy" (field notes, June 2012). He said that the best smart meters he had seen were designed by behavioural scientists, and mentioned how interaction designers work with intuitive information feedback such as 
colour-changing light bulbs. This piece of information was accompanied by surprising looks at the faces of the audience, who had clearly not heard of this kind of ambient technology before. A representative from the Danish Technological Institute half proudly, half self-ironically told that they had just hired two anthropologists "to take care of the more humanist perspectives on smart grid" (field notes, June 2012). This call for specialist knowledge on humans was also felt by first author who was promptly re-cast from ethnographic researcher with "investigating how smart grid developers work with the notion of the user"15 into an expert on how to get the humans 'on board' the development.

By participating in the delegation trip first author had become part of the 'smart grid family' together with the engineers and the designers. Below, we link this call for experts representing the ordinary electricity user to a discussion on how smart grid development might include the concerns of ordinary European citizens differently (than through expert spokespersons). But first we need to bring another smart grid object into view.

\section{The Smart Grid Family}

With a metaphor presented by Helmut Smith the relations between smart grid actors became a matter of 'family relations'. After having named EEnergy a 'smart grid family' who is collaborating to realize an intelligent energy infrastructure in Germany, Helmut Smith ends his presentation asking the Danish delegates "Where are you in the family?" (field notes, June 2012). The immediate reaction from the audience is a disconcerted laughter and the dialogue that Smith prepares the ground for is not really taking off. For the first time during the day the atmosphere in the room gets a bit awkward. We can only speculate about the significance of the Danes' disconcerted laughter (cf. Verran, 1999). Recall how the purpose of the delegation trip was "to create Danish-German partnerships", but the move from the notion of partnership to the notion of family is not immediately digestible for the Danes. Nevertheless, the metaphor keeps reappearing through jokes about 'being family', and seems to grow on the Danes during the next couple of days.

We don't know whether Smith has read his deceased compatriot the philosopher Ludwig Wittgenstein who developed parts of his philosophy around the notion of 'family resemblance' (Familienähnlichkeit) in order to explain how otherwise very different things can be characterised and recognised under a shared umbrella term such as 'games. But Smith explains how he finds the concept of a 'smart grid family' a constructive way to deal with what he counts as one of the major challenges in smart grid development. It is a challenge, he says - and this is confirmed by the Danish delegates - to gather the many heterogeneous actors working on each their parts and interests in smart grid and to provide them with a feeling of working towards the same goal. Especially, he says, "it is challenging to make the conservative energy sector collaborate with the innovative ICT sector" (field notes, June 2012).

This particular problematization of smart grid innovation as happening in a situation characterized by family resemblance and shared goals we see as a process in which an ensemble of relevant actors is being cast. Philosopher of science Kathryn Pyne Addelson (2002) argues that issues of public controversy are "not just objective conditions lying in wait for alert citizens or professionals to discover" (Addelson 2002: 121), but are made into issues of public concern. This is done by gathering influential and authoritative actors around the given issue. The resulting network is what she refers to as an 'ensemble cast' 
(Addelson 2002: 119). In this way, Addelson develops a language for describing how experts and the public are being configured (or cast) along with the problem they seek to solve. In this process it is being sketched out who can act and in relation to what particular problem.

Inspired by Addelson we see the delegation trip as an attempt to define the problem of smart grid and name the actors that might participate in solving this problem. Addelson highlights how the ensemble cast is in a privileged position to define what issues are turned into public problems:

[P]ublic problems are particular definitions of suffering, dangers, and risks made by particular people, and suited for particular reasons. They label what and who is the problem.

(Addelson 2002: 128).

Addelson argues that a crucial part of constructing a public problem is to show how the problem can be managed and/ or solved through science, engineering, design, or related methods. Thus, in this view problem-posing is an inherent part of problem-solving. However, if a crucial element of constructing a public problem is to be able to demonstrate how the problem can be managed and/or solved through engineering and design, the smart grid family is not a very sharp or effective tool in doing the casting work. It simply cannot be considered a tool for making smart grid development emerge as a manageable task. Similarly, the metaphor of smart grid as a jigsaw puzzle, which we presented in the introduction, is a somewhat vague tool for framing smart grid as a manageable public problem. The puzzle depicts a world in which smart grid development (the puzzle) is complicated, but doable. But only when the missing pieces - collaborators or technologies - are found or invented.
So what do the metaphors do? What does their efficacy amount to? Both the jigsaw puzzle and the family present a 'whole', in which actors are nevertheless unmarked and undefined. Both tropes encourage involvement of new not-yet-existing and not-yet-foreseeable participants. Might this vagueness be an attempt to call on publics to emerge? Such a conception of the public has been presented by Noortje Marres retelling pragmatists John Dewey and Walter Lippmann's thoughts on how publics come into being. She argues that publics emerge exactly when problems become too complex and where the experts do not have any answers or clear definitions (Marres, 2005).

Attending to the smart grid and its related objects as a 'thing' allows us to attend to smart grid innovation as a matter of emerging ontology. Emerging in relations between models, experts, metaphors, a princess, an ethnographer, puzzle and family, is innovation as happening in 'a space between seeing and saying' (Hetherington, 2011) ${ }^{15}$. Smart grid innovation is not only about solving a problem lying in wait to be solved, but just as much a matter of opening up a an imaginative space of opportunity.

When we suggest that the smart grid family enacts an innovation process happening in such an imaginative space, we also advocate for methods that see innovation as a matter of collecting actors and building 'families' in order to make the smart energy infrastructures emerge in this space in between. The imaginative space is created in events or relation-work such as the delegation trip, and the space is constituted by the different objects and actors brought into the space. When we choose to call it an imaginative space of opportunity it is because we want to emphasise that the space created at the delegation trip is only one out of many different spaces, which could potentially be created. We want to remind the reader 
that the space could be constituted in many different ways. However, before we return to a potential expansion of the participatory potentials in smart grid innovation, we explore how family-building is also a matter of making 'non-relations'.

\section{Too Complex for the Public?}

Recalling Addelson's point about the ensemble cast we are inspired to ask: 'Who and what is not part of the smart grid family?' Who is not a part of the 'ensemble cast' that gets to formulate what the public problem is, and how it is solved?

Both Smith and Møller-Jensen emphasize that the prosumer should experience the complex systems (be it separate worlds or nodes in a network) as one whole and coherent system; the prosumers are not meant to see the complexity and messiness of the system, which is already to a certain extent too messy for the experts to deal with. In both models prosumers 'live' outside of the system. In Spirae.dk's model this is depicted as users being placed up in a cloud. Thus, users are placed at the end point of the innovation process, and not included into the spaces where problem-posing nor problem-solving is happening. Referring to Noortje Marres' work we may say that users are only participating at a somewhat instrumental level (Marres, 2012: chp. 2).

Thinking about smart grid as an infrastructure for the general public to inhabit, it appears odd that the prosumers, that is the public ${ }^{16}$, is not invited to take part in 'casting the ensemble.' Instead, they are imagined to magically become 'smart' once the system is in place. This version of soft technological determinism takes users into account without really offering a possibility to participate in determining major issues of concern. The public is not invited into the innovation process. Though smart grid development is framed as an issue concerning everybody, we also observe a 'non-relation' between smart grid developers and potentially affected user groups. Therefore, besides gathering and including actors during the delegation trip, we will add that the smart grid family metaphor furthermore functions as an apparatus for excluding and making nonrelations to actors. The metaphor thus participates in constructing smart grid development as an imaginative space of opportunity and closure.

We are not the first researchers studying electricity infrastructure development who have stated that publics are not included (enough) in the innovation process. Several studies show that 'imagined publics' play a role for infrastructure developers, but that publics are often only included as imagined threats that can disapprove and protest about prices, aesthetics and health issues (often referred to as NIMBY-ism). An inclusion of publics thus mainly serves the purpose to counteract mistrust, opposition, and scepticism for emerging technologies and to create public acceptance (Cotton \& Devine-Wright, 2010; Maranta et. al., 2003; Walker et. al., 2010).

These studies show that energy network developers only (if at all) involve publics far downstream the innovation process when important decisions have already been made and when the technology is largely stabilized and black-boxed. Publics therefore, are only involved in less fundamental decisions concerning aesthetics, prices, consumer behaviour, etc. More essential issues of innovation are left to chains much further upstream in the process and are exclusive to a closed environment of experts (Cotton \& Devine-Wright, 2010; Walker et. al., 2010). Cotton and Devine-Wright find it problematic that industry often has a rather homogeneous and black-boxed concept of the public. A reason for categorizing users as consumers, rather than publics, they say, is that the infrastructure developers do not like using the concept of publics, because it invokes connotations to public opinion, 
which is mostly considered threatening to the development process (Cotton \& DevineWright, 2010).

Along the lines of the above studies and in concert with our findings, Maranta et al. argue that the 'imagined lay persons' seldom have much to do with reality, but are rather 'functional constructs in expertise'; "a more or less made up conception of the kind of lay person they consider as their principal" (Maranta et. al., 2003: 151). As a result, users or publics become merely a part of the technical solution rather than being receivers of the technology. This rather techno-centric model for innovation resembles the smart grid developers, who, though they recognize that somebody with expertise in humans needs to be involved, did not think that the human-experts (and definitely not regular users) should be involved in the innovation process before the technical part is in place and working. Publics should not be introduced before the technological system is coherent and fully working. The problem in this way of thinking, however, is that it fails to recognize how user identities co-evolve with the technological systems (Jensen \& Winthereik, 2013, chapter 3 and 4).

As many STS studies have pointed out there is an epistemic asymmetry between experts as the knowing ones and lay people as ignorant. Experts see a need to sustain this divide in order to hold on to their authority and legitimize their own function in society. "The epistemic divide makes experts and lay persons live in different worlds regarding what they think this very world is" (Maranta et. al., 2003: 151). Maranta et al. argue that the deficit model is to perceive users as passive, ignorant, selfish, and disinterested, and that the public has to be educated to take an informed opinion (Maranta et. al., 2003: 162). Whereas this also seemed to be the common conception among the smart grid developers on the trip - that publics are generally not interested in 'the problem of smart grid' and thus cannot be involved we see this as a paradox because the success of smart grid is framed as largely dependent on an interested and engaged public. In this rather top-down innovation model publics are not, to reference Addelson, invited into the work of defining and constructing what the public problem is and thus how it should be solved. Instead of engaging publics themselves, the smart grid developers are advertising for human-experts to join the family. But what would happen if publics were invited to take part in the innovation on a much earlier stage of the development, before smart grids are stabilized and made coherent as a finished object (Jensen, 2010)? What if they were invited into the family and into process of defining smart grid as a public problem?

\section{Complex Enough for New Ensemble Casts}

Today's electricity users are not 'smart grid ready', because they have no idea what a smart grid is! (Siemens representative, field notes, June 2012) ${ }^{17}$

Above we argued that during the delegation trip smart grid innovation was constructed as a problem with political, legal, ethical concerns mainly for experts to solve. Ending this article we propose arguments for why it is important to invite 'alien' and problematic actors into the smart grid family, whose views are not first translated by specialists with 'know-how on humans'. These actors "have no idea what a smart grid is", but it still affects them as they are implicated in the emerging smart grid infrastructure. So how to take these actors into account?

In her text Issues spark a public into being - A key but often forgotten point of the Lippmann-Dewey debate (2005) sociologist, Noortje Marres makes a thorough reading of John Dewey and Walter Lippmann's 
debate in the 1920'es. She uses this debate to paraphrase the notion of the 'public problem. Following this text we suggest that embracing 'ignorant,' yet implicated publics, could be generative to the innovation process.

Similar to Addelson's claim that public problems do not lie in wait to be found but have to be constructed, Dewey and Lippmann says that 'publics' do not exist as pre-given entities, but are 'sparked into being. This happens when issues become so complex, strange and unfamiliar that experts do not have clear answers so them. "Lippmann and Dewey showed that there is no reason to believe that complex affairs cannot be dealt with democratically. But to see this requires an understanding of political democracy different from the modern one. Accepting this challenge, Lippmann and Dewey arrived at the argument that complex issues actually enable public involvement in politics" (Marres, 2005: 208) ${ }^{18}$.

Whereas our informants find smart grid too complex for potential users to cope with, complex and unfamiliar problems could in fact be suited for 'ignorant' publics to take care of. When traditional institutions and experts take care of an issue the public can sit back and relax with no need to engage. But when people suddenly feel that any authorities do not deal with an issue affecting them or that experts have no solutions to the problem, the issue becomes a matter of concern. "The hardest problems are problems which institutions cannot handle. They are the public's problems." (Lippmann, 1927: 121 in Marres, 2012: 47).

As we have shown, smart grids are imagined to be complicated technological infrastructures for publics to inhabit, and these complicated entanglements will undeniably affect ordinary people. Following Marres' view on how public problems come into being smart grid is exactly not being constructed as a 'public problem, because experts take care of the issue by providing answers and by maintaining a non-relation to publics. All doubts and problems are kept inside the closed space of expert innovation networks, and ordinary citizens should only be engaged in smart grid development insofar as their voices are mediated by 'experts on human beings.'

But when problems become relevant to people they gather around them and this is how a public come into existence (Marres, 2005; see also Latour, 2005). The public is thus defined in terms of a particular modality of issue involvement and issue relevance. Maybe, ordinary people are not necessarily as uninterested and unengaged in their energy consumption, as the smart grid developers tend to think. Maybe they just don't feel the relevance - maybe, as the above field note quote implies, publics are not involving themselves in smart grid, because they do simply not know it exists. As experts have defined smart grid as a problem for experts so solve and as the electricity grid has always been an invisible infrastructure, which consumers have not engaged with, potential future users are easily framed as ignorant and uninterested (on invisible infrastructures see Bowker, 1995; Cotton \& Devine-Wright, 2010; Hargreaves et. al., 2010).

In his book Phantom Public (1927) Lippmann (much in line with Maranta et. al. 2003) says that the public is 'a partly imaginary entity'; an 'alien' or an 'abstract creature' (Marres, 2012: 46-50). "What if the public is indeed a problem what if this problem must be appreciated as a problem before it can be sorted out?" (Marres, 2012: 57 , original emphasis). A way to do this, again following Marres, is to think about potential future smart grid users as 'affected publics', and not only as instrumental entities that can and should be changed 
by technology. The publics' opinions and concerns should not only be tolerated and accommodated, but they should be seen as valuable and generative to the innovation of smart grids (Marres, 2012, Chapter 2). Doing so, however, entails embracing (rather than fearing) the publics' disagreements and conflicting opinions and concerns. Is this not exactly the promise of the family metaphor? Families are both about close and distant relationships. Doesn't the family metaphor exactly hold the promise of being able to include conflicting actors and discrepant publics? ${ }^{19}$

Marres says that publics are 'intimately affected outsiders'; they are both inside and outside the problem. Both alien to and implicated in public problems - both inside and outside the family, we might add. Because of this double-position they can often come up with unfamiliar strategies for solutions and distinctive contributions (Marres 2012: 51). This, we will argue, provides a good argument for including potentially affected publics into the smart grid family and for inviting them into the work of posing and articulating which kinds of problems smart grids are how they could potentially be solved.

To end with a couple of examples indicating openings in this direction, the Siemens representative ends her presentation of a study done among electricity consumers, by saying that a recent survey by her company showed that 'consumers are more than smart grid ready' For example they have lots of good ideas for how future smart green homes should be designed. When asked to draw their future homes what appeared were highly connected homes with solutions not so far from the experts' solutions. The consumers were less concerned with how to make energy consumption flexible. The publics' suggestions thus expressed other problems, other wishes, and other concerns.
Just like people in the survey emerged to Siemens as a public with relevant views - much to the surprise of the Siemens representative - the STS researcher emerged as someone with a relevant position for one of the more technically oriented delegates. In her role as university representative she participated in "enriching historical and technological imagination" (Jensen 2010:43) of one of the company representatives, as during the evaluation of the workshop at Siemens one of the participants pointed towards the first author and said:" I have learned that technology ought to be considered as both a social and political entity". Other delegates from time to time mentioned to her that she was the one making smart grid (due to her being framed as one of the experts on human beings).

We have here been concerned with emerging 'relative' positions in a proposed smart grid family. Yet, the list of possible casts could be extended to for example artists concerned with electricity consumption. There are a growing number of artists who have taken up electricity and the engineering of renewable energy infrastructures as a medium to work with. The art- and design competition Land Art Generator Initiative invites artists into the innovation space by challenging them to create large-scale public art sculptures, which also function as renewable energy power plants. The project encompasses the disciplines of art, architecture, urban planning, renewable energy science, and ecological conservation ${ }^{20}$. In collaboration with the Finnish capital's energy company Helsinki Energy the artist duo $\mathrm{HeHe}$ has visualised and made public the electricity consumption of Helsinki citizens in a spectacular, interactive green cloud hovering in the dark sky over a power plant (Nuage Vert, 2008). And media artist Usman Haque has designed a network devise (Patchube, 2007-2011), where the public can 
store and connect various data (pollution, energy consumption, $\mathrm{CO}_{2}$ emissions, weather date, etc.). The data can be used by the public to create new and meaningful 'out-of-the-box apps', and Haque's aim is "for individuals to take control of their own data and design their own connections in smart homes" and thus to "make smart people out of dump objects" (Haque, 2011) ${ }^{21}$.

In suggesting we acknowledge the emergence of smart energy infrastructure as an imaginative space of opportunity and we propose seeing any opportunity for participation as a step in the right direction. A Siemens representative seeing consumers differently as people with a voice. First author's presentation being reflected on by delegates framed as smart grid experts. Both are examples of emerging infrastructures for the discussion of smart grid that opens up the problem-solution nexus somewhat ${ }^{22}$. Including artists in the staging of 'alien' voices may include new and imaginative family members into the smart grid family.

\section{Conclusions}

Problems of relevance [...] suggest a dynamic political ontology in which the process of the specification of issues and the organization of actors into issue assemblages go hand in hand. Here the composition of the public - which entities and relations it is made up of - must be understood as partly the outcome of, and as something that is at stake in, the process of issue articulation. (Marres, 2012: 53).

We would like to end by suggesting seeing smart energy futures as a public problem. By looking at the smart grid models as inscriptions we saw how they construct (partly similar, partly different) subjectpositions for future electricity consumers, who are imagined to become more engaged and active in their energy consumption and production. This finding made us speculate on the mismatch between, on the one side, experts' imagination of active prosumers and, on the other side, an absence of actual users/humans in the innovation space.

In analysing the relations between smart grid objects, their protagonists, and their audiences, we found that innovation emerges in a collective process of making relations and non-relations. In this context, the informants' own metaphor, the smart grid family, seemed to have three effects: Firstly, it gathered a heterogeneous 'ensemble cast' of smart grid developers making them collaborate on 'one and the same' project. Second, it called for new experts to become part of the family. And third, it created a division between who is part of the family (experts) and who are not (non-experts). During the delegation trip smart grid emerged as a problem for the experts to solve. The experts then framed the problem as a matter of getting more experts involved, for example experts on human beings. The inclusion of first author into the family indicates that the family is not an entirely closed space, but the expert role was important in order to gain impact. We discussed how to open up the space to new and differently imaginative family members.

As we have seen in other studies, infrastructure developers are reluctant to engage publics in the innovation process because they fear that the many divergent opinions can slow down the process. We could add that the danger of opening up the ensemble cast to new voices might be that the yet very partially existing smart grid be articulated and performed in multiple and in-coherent ways, which makes it difficult for it to gain in reality. However, Latour argues, "an arena, can be very sturdy, too, on the condition that the number of its participants, its ingredients, nonhumans as 
well as humans, not be limited in advance. (Latour, 2004: 246). It is important to keep the 'ensemble cast' open to new and unforeseeable actors because those who are considered 'aliens' might articulate the problems differently than the 'experts' and thus lead to very different solutions ${ }^{23}$.

Recalling Addelson's proposition that "The experts play important roles in determining who the participants [in a public problem] are." (Addelson, 2002: 129), we have argued that, instead of holding on to the epistemic asymmetry between experts as knowledgeable and publics as ignorant and uninterested, experts can benefit from inviting new ensemble casts into the smart grid family. However paradoxical it might seem, we argue that a way to make publics part of the family is to frame smart grid as an 'unfamiliar' problem, that is a problem to which experts do not have any fixed solutions - but also to articulate smart grid as a problem to which they do not even know the character of the problem. We argued that it is crucial to invite publics to take part in articulating smart grid as a public problem, but even of they are not invited they may form concerned groups around smart grid development anyway. This makes it important to emphasize that we are not talking about user-involvement in the sense that publics are included as knowledge-carriers whom the experts can 'unpack' and find answers to their problems. It is not (only) about finding human-experts, who can mediate between humans and technology and who can reconfigure consumers into prosumers. Rather than fearing, we urge the smart grid developers to embrace the 'alieness' and 'unfamiliarness' of 'humans' in their unruliness, because we believe that this can bring other/new concerns to the complex and problematic 'thinginess' of smart grid. We believe that this can be generative to the innovation process and hopefully generate an infrastructure for general publics to inhabit.

Including other publics can bring new and alien ways of articulating energy futures as public problems and maybe thereby bring very different problems, concerns, and solutions into the arena of smart grid innovation. Allowing for nonexperts' problems to become relevant in the development of smart grids, and other emergent technologies, can result in a more dynamic innovation process. Therefore we argue that studying as well as innovating new 'things' is a matter of focussing more on how problems and issues are posed and by whom. This, we believe, can lead to a more dynamic, and less techno-centric and less top-down innovation process - a relational ontology of green energy futures.

\section{References}

Addelson, K.P. (2002) 'The Emergence of the Fetus', in C. L. Mui \& J. S. Murphy (eds), Gender Struggles. Practical Approaches to Contemporary Feminism (Boulder, NY: Rowman \& Littlefield Publishers): 118-36.

Akrich, M. (1992) 'The de-scription of technical objects', in W. E. Bijker \& J. Law (eds) Shaping Technology/Building Society: Studies in Sociotechnical Change (Cambridge, Mass.: MIT Press): 205-24.

Bowker, G.C. (1995) 'Second Nature once Removed: Time, Space and Representations,' Time \& Society, 4(1): 47-66.

Bowker, G.C. \& S.L. Star (2000) Sorting Things Out: Classification and Its Consequences (Massachusetts: MIT Press).

Cotton, M. \& P. Devine-Wright (2010) 'Making electricity networks "visible": Industry actor representations of "publics" and public engagement in infrastructure planning, Public Understanding of Science 21(1): 17-35.

Dantec, C.a.L. \& C. DiSalvo (2013) 'Infrastructuring and the formation of 
publics in participatory design', Social Studies of Science 43(2): 241-64.

Deleuze, G. (1995) Foucault (Minneapolis: University of Minnesota Press).

Energinet.dk. (2011) 'Denmark Opts for Smart Grid', (Denmark) Retrieved from http://energinet.dk/ SiteCollectionDocuments/Engelske dokumenter/Forskning/SmartGrid in English.pdf

Haque, U. (2011) 'Smart People, Dumb Objects' (UK: TedX Leeds) Retrieved from http://tedxtalks.ted.com/video/ TEDxLeeds-Usman-Haque-Extreme-C

Hargreaves, T., M. Nye \& J. Burgess (2010) 'Making energy visible: A qualitative field study of how householders interact with feedback from smart energy monitors', Energy Policy 38(10): 6111-19.

Hetherington, K. (2011) 'Foucault , the museum and the diagram, The Sociological Review 3(59): 457-75.

Jensen, C.B. (2010) 'Ontologies for Developing Things: Making Health Care Futures Through Technology' (Rotterdam: Sense Publishers).

Jensen, C.B. (2013) 'Continuous Variations: The Conceptual and the Empirical in STS', Science Technology And Human Values (http://sth.sagepub.com/content/ early/2013/09/09/0162243913502866. abstract).

Jensen, C.B. \& B.R. Winthereik (2013) Monitoring Movements in Development Aid: Recursive Partnerships and Infrastructures (Cambridge and London: MIT Press).

Latour, B. (1976) 'On the Partial Existence of Existing and Non-existing Objects', in D. Lorraine (eds), Biographies of Scientific Objects (Chicago: Chicago University Press): 247-69.

Latour, B. (1986) 'Visualisation and Cognition: Drawing Things Together ", Knowledge and Society 6: 1-40.

Latour, B. (1992) 'Where are the Missing Masses? The Sociology of a Few Mundane Artifacts', in W. E. Bijker \& J. Law (eds), Shaping Technology/Building Society: Studies in Sociotechnical Change (Cambridge, Mass.: MIT Press): 209-26.

Latour, B. (1999) Pandora's Hope: An Essay on the Reality of Science Studies (Cambridge, Mass.: Harvard University Press).

Latour, B. (2004) 'Why Has Critique Run out of Steam? From Matters of Fact to Matters of Concern', Critical Inquiry 30(30): 22548.

Latour, B. \& P. Weibel (2005) Making Things Public: Atmospheres of Democracy (MIT Press).

Maranta, A., M. Guggenheim, P. Gisler \& C. Pohl (2003) 'The Reality of Experts and the Imagined Lay Person', Acta Sociologica 46(2): 150-65.

Marres, N. (2005) 'Issues spark a public into being. A key but often forgotten point of the Lippmann-Dewey debate', in B. Latour \& P. Weibel (eds), Making Things Public (Cambridge, Mass.: MIT Press).

Marres, N. (2012) Material Participation: Technology, the Environment and Everyday Publics (Hampshire: Palgrave Macmillan).

Mol, A. \& J. Law (2002) Complexities: Social Studies of Knowledge Practices (Durham, NC: Duke University Press).

Nyborg, S. \& I. Røpke (2013) 'Constructing users in the smart grid - insights from the Danish eFlex project', Energy Efficiency 6(4): 655-70.

Schick, L. \& A.S. Witzke (2011) 'Powering Ecological Futures', in ISEA, Istanbul (Istanbul: ISEA). Retrieved from http:// is ea 2011 . sabanciuniv.edu/paper/ powering-ecological-futures

Stengers, I. (2005) 'The Cosmopolitical Proposal', in B. Latour \& P. Weibel (eds), Making Things Public (MIT Press): 9941003.

Suchman, L. (2007) Human-Machine Reconfigurations: Plans and Situated Actions (Cambridge: Cambridge University Press). 
Verran, H. (1999) 'Staying true to the laughter in Nigerian classrooms', in J. Law \& Hass (eds), Actor Network Theory and after (Blackwell Publisher / The Sociological Review): 136-55.

Walker, G., N. Cass, K. Burningham \& J. Barnett (2010) 'Renewable energy and sociotechnical change: imagined subjectivities of "the public" and their implications,' Environment and Planning A 42(4): 931-47.

Winthereik, B.R., N. Johannsen \& D.L. Strand (2008) 'Making technology public: Challenging the notion of script through an e-health demonstration video, Information Technology \& People 21(2): 116-32.

Winthereik, B.R. \& H. Verran (2012) 'Ethnographic Stories as Generalizations that Intervene', Science Studies 25(1): 37-51.

\section{Endnotes}

1 Denmark has four innovation centres around the world (Shanghai, Hong Kong, Silicon Valley and Munich) aiming at strengthening collaborations between Danish and international businesses. This is indicated on the web page the following way: "We help you innovate and grow through international partnerships" (http:// icdk.um.dk/en/).

2 http://icdk.um.dk/en/aboutus/innovationcentres/munich/ innovation-projects/smartgreenhome/

3 The metaphor was used several times during the trip and it is often used in smart grid documents, at smart grid events and in the media.

4 In a recent smart grid project in Denmark anthropologists were hired in order to investigate how users or humans were acting with smart grid technologies, in this particular case the heat pump. For an analysis of this study see Nyborg \& Røpke 2013.

5 The concept of the prosumer derives from new media and is a portmanteau of consumer and producer. Below we will elaborate further on the term and its meaning in the context of smart grid. Whereas the prosumer was a topic during the trip and in the early development of smart grid, it has since vanished from the smart grid discourse.

6 In what follows we employ notions of the user, consumer, prosumer, people, humans and lay people to account for the complexity of the social groups that are partly imagined, partly already existing.

7 Using the image of the development of an infrastructure as a 'birth', Jensen here paraphrases Michel Foucault in The Birth of the Clinic.

8 In 2010 the Danish Ministry of Energy, Climate and Building initiated a smart grid network consisting of a number of important players within electricity infrastructures, including universities, the Danish Energy Association and the state-owned, national transmission system operator, Energinet.dk. The aim of the network has been to develop a shared 'smart grid strategy' (released May 2013), which describes a road map for Danish smart grid development. During the three years a number of reports have been released together with continuous events. First author has been doing her fieldwork following this process and reading the reports produced. One central document that has been especially influential to the fieldwork is the pamphlet 'Denmark Opts for Smart Grid', made by Energinet.dk. The pamphlet outlines state of the art of smart grid research and implementation in Denmark 2011. 
9 Each day offered one or two visits to central developers of smart grid. Besides Siemens and EEnergy, which will be described in the paper, other institutions visited included Frauenhofer Institute, Munich Innovation Network, and Munich Stadtwerke. Danish participants represented five small enterprises, the Danish Technological Institute, Danish Technological University and then the first author, who represented a strategic research initiative entitled Energy Futures at the IT University of Copenhagen.

10 http://www.e-energy.de/

11 Even though the German, with the Energiewende policy legislated by the Germany government 2011, has decided to phase out all nuclear power plants by 2020, it appears in EEnergy's model.

12 The term 'smart energy' is commonly used by smart grid developers.

13 This conceptualization of the smart grid as an 'energy stock exchange' is commonly shared by most smart grid projects. The energy stock exchange is imagined to collaborate with existing energy trading systems such as the Nord Pool Spot and EPEX Spot (European Power Exchange), where local traders buy and sell electricity and power is being transported between countries and thereby help stabilizing the national grids.

14 As part of the participation first author had to write a page about her own work with smart grid, in which she stated that she had "investigating how smart grid developers work with the notion of the user".

15 In order arrive at the concept of an 'imaginative space of opportunity' we have been inspired by Hetherington 2011 and by Gilles Deleuze's concept of 'diagram', which he develops from Michel Foucault (Deleuze, 1995).

16 As is also noted by Cotton and DevineWright (2010), when it comes to electricity infrastructures in the context of the Western world, electricity is so pervasive that it cannot be compared to regular goods, which are chosen or not chosen by the consumer. We are born into the electricity infrastructures and therefore talking about future prosumers must refer, not to a specific user group, but rather to the general public.

17 This comment also resembles first author's general observations through her two years of working with smart grid. When explaining to people that she researches smart grid, very few of these 'lay persons' have ever heard about the concept.

18 Though Dewey and Lippmann talk about politics the same counts for engineering experts and designers, as Marres also discusses in her book Material Participation (2012)

19 As Marilyn Strathern argued during her keynote presentation at University of California Santa Cruz on February $28^{\text {th }}$, 2013 (Emerging Worlds Lecture Series with Donna Haraway), 'the relative' is an interesting figure when thinking about (kinship and other kinds of) relations. For our purposes here, we might think of lay people as 'relatives', who, however different and 'strange' they are, should nevertheless be invited to the family gatherings. Maybe they bring something new and unexpected to the table.

20 http://www.landartgenerator.org

21 For further discussion of the two artworks see Schick \& Witzke, 2011.

22 Dantec \& DiSalvo (2013) make similar argument when they make a distinction between what they call 
'infrastructuring' and participatory design. Also building on Dewey and Marres they say that in participatory design users are included into already known issues and their role is to answer already defined problems. 'Infrastructuring' on the other side is a matter of including publics in order to discover unknown issues.

23 Similarly, Isabelle Stengers argues for an inclusion of 'the idiot' into the production of knowledge and engineering exactly in order to 'slow down' reasoning. She argues that the idiot's strange mumbling might be generative to the process (Stengers, 2005).
Lea Schick

IT University of Copenhagen

Rued Langgaards Vej 7

DK-2300 Copenhagen

Denmark

leaschick@itu.dk

Brit Ross Winthereik

IT University of Copenhagen

Rued Langgaards Vej 7

DK-2300 Copenhagen

Denmark

brwi@itu.dk 